\title{
"WHY DON'T YOU CARE ABOUT CSR? - A QUALITATIVE STUDY EXPLORING THE LIMITED ROLE OF CSR IN CONSUMPTION DECISIONS
}

\author{
Magdalena Öberseder, WU Vienna, Austria \\ Bodo B. Schlegelmilch, WU Vienna, Austria \\ Verena Gruber, WU Vienna, Austria
}

\begin{abstract}
There is an unresolved paradox in the role of corporate social responsibility (CSR) in consumer behavior. On the one hand, consumers demand more and more CSR information from corporations. On the other hand, research indicates a considerable gap between consumers' apparent interest in CSR and the role of CSR in purchase behavior. This paper attempts to shed light on this paradox by drawing on qualitative data from in-depth interviews.

The findings show that the evaluation of CSR initiatives is a complex and hierarchically structured process. Consumers distinguish between core, central, and peripheral factors. This paper describes these factors in detail and depicts the complexity of CSR assessment by consumers. A model clarifying the relationship between core, central, and peripheral factors is used as a basis for discussing the implications of the research findings. To this end, the paper contributes to a better understanding of the role of CSR in consumption decisions.
\end{abstract}

References available upon request 